\title{
Emotional Burnout: Prevalence Rate and Symptoms in Different Socio-Professional Groups
}

\author{
Vitalii Y. Bocheliuk ${ }^{1,}$, Nataliia Y. Zavatska ${ }^{2}$, Yuliia O. Bokhonkova ${ }^{2}$, Marianna V. Toba ${ }^{2}$ and \\ Nikita S. Panov ${ }^{3}$
}

${ }^{1}$ Zaporizhzhya National Technical University, Zaporizhzhia, Ukraine

${ }^{2}$ Volodymyr Dahl East Ukrainian National University, Severodonetsk, Ukraine

${ }^{3}$ Khortytsia National Educational Rehabilitation Academy, Zaporizhzhia, Ukraine

\begin{abstract}
Objective: The relevance of the subject matter is connected with the emotional burnout and its long-lasting negative consequences for both the individual and society becoming commonplace.

Background: The paper covers the psychological reconstruction of the concept of "burnout" in terms of its implicit understanding and differentiated diagnosis.

Method: The consolidated empirical data on the commonness of burnout among various categories of employees obtained using the $\mathrm{MBI}$ questionnaire. The descriptive statistics were presented for nine different professional groups (total of 441 people) of different age, degree of personal responsibility and emotional involvement in their job - the frequency analysis of expressiveness of emotional burnout syndrome performed in the context of the proceduraldynamic model.

Results: Results revealed that the symptoms of burnout are quantitatively and qualitatively vary in different occupational settings. Based on the content analysis of the data obtained through face-to-face psychological counselling of clients, a list of manifestations and experiences was developed, accompanying burnout complaints as a component of a difficult life situation: emotional and motivational-semantic sphere, life position, behavioural, and psychological and physiological aspects.

Conclusion: Attention was drawn to the necessity of clarification of social-psychological norms and clinical signs, which reliably and differentially diagnose its symptoms (in contrast to fatigue, depression or normative age crises). The conclusions provide suggestions and solutions on the principles of psychological prevention and assistance (self-help) in situations of emotional burnout.
\end{abstract}

Keywords: Fatigue, emotional burnout (fatigue), depersonalization, cynicism, decline in professional achievements.

\section{INTRODUCTION}

Nowadays, the problem of emotional burnout has not just scientific significance, but also great social resonance. Burnout has become synonymous with the 21st century; the subject matter is actively discussed in the press, social networks, among public figures. Researchers all over the world are registering an "epidemic" of burnout - general exhaustion, accompanied by severe emotional, cognitive and social disorders [1]. K. Maslach, who is a leading expert in the study of this phenomenon, identified a triad of features that determine the presence of burnout in humans: 1) emotional exhaustion, 2) cynicism, 3) a sense of inefficiency, devaluation of personal achievements [2]. Historically, burnout has been seen as a risk associated with "people-oriented" work, assistance provision, close interpersonal contacts. It concerned the socio-economic professions: healthcare, education, psychological practice, services, law enforcement,

*Address correspondence to this author at the Zaporizhzhya National Technical University, Zaporizhzhia, Ukraine; Tel: 06117642506;

Fax: 0617642141; E-mail: t.volynets07@gmail.com management, etc. Over time, the context of burnout has expanded to include a growing range of stressful occupational and organizational factors. Finally, burnout was recognized to involve any area of work, where a person can sense and experience the three sub-spaces of burnout, regardless of contact with others [2-4].

According to World Health Organization (WHO), psychosocial stress in the workplace is connected with an imbalance between, on the one hand, high demands (working time, limited time, control, responsibility) and human effort, and on the other hand, reward, recognition and rest [5]. If professional requirements are too high and professional resources are insufficient, physical and psychological health deteriorates, motivation to work is reduced, which ultimately leads to exhaustion.

This is more than fatigue due to prolonged stress or impediment to professional growth. Burnout syndrome is accompanied by changes in the functioning of the endocrine system and brain structures. Magnetic resonance imaging (MRI) scans of the brain regions 
involved in the production and processing of emotions revealed an increase in the tonsils and a weakening of the connections of this structure with other areas of the brain associated with distress. This explains the complexity of controlling negative emotions and the exacerbated response to stress in people with burnout [6]. I. Savic's experiments confirmed changes in the anatomical structure of the brain: accelerated ageing and "wear and tear" of the areas involved in modulating stress responses. Excessive activation of the tonsils leads to a gradual thinning of the cortical layer (medial prefrontal cortex) and shortening of the anterior lingual gyrus, which in turn causes memory and attention problems. All these signs accompany the normal ageing process, but in persons with burnout, they are more pronounced. Excessive excretion of glutamate in the process of stress has a neurotoxic effect on the grey matter of the brain and leads to a decrease in its volume, destroys neural circuits [7]. By reducing cognitive function, people are less likely to solve problems and more vulnerable to the adverse effects of stress, which in turn impairs the quality of work and life, increasing burnout. A "vicious circle" of neurological dysfunction emerges [8].

Upon burnout, the neuroendocrine system of regulation (the hypothalamus-pituitary-adrenal axis), responsible for the release of the stress hormone cortisol, is disrupted. Under normal stress, cortisol stimulates the activity of many organs and systems, providing adaptation, and then returns to the basic level. In the event of burnout, when cortisol levels rise too often, the body cannot return to normal. Hence, a protective reaction of hypocortisolism (reducing cortisol production to abnormally low levels) occurs, as if the body's response system had indeed been burned. Clinical studies show reduced levels of morning cortisol in patients with burnout; thus, from the very start of the day, people experience a lack of strength and energy. Hypocortisolism, in turn, leads to a cascade of potential health issues, risk of coronary heart disease $[9,10]$.

At the beginning of 2019, Ukraine was flooded with an information wave that the WHO had included burnout in the International Classification of Diseases (ICD), meaning that the disorder had acquired the status of an official medical diagnosis [11]. This news was widely circulated and picked up by the media, so objection of the Ministry of Healthcare remained next to unnoticed [12, 9]. In fact, occupational burnout is referred to in the section "Factors affecting public health and access to healthcare facilities". It is considered as an additional circumstance or problem that affects health and should be kept in mind upon seeking help for any disease, but is not a disease in itself. According to ICD-11, burnout results from chronic workplace stress that has not been successfully overcome. The term is used in a professional context and should not be used to describe the experience in other areas of life [13].

Contrary to the last observation, psychological practice "opens up" all new varieties of burnout in a broad life context that need more pressing scientific analysis (thus, L. Petranovskaya and other family psychologists popularize ideas about parental burnout) [14]. There is a contrary opinion: Yu. R. Vagin considers burnout as a far-fetched issue, which hides professional unfitness, unwillingness to work with people, idealistic and imaginary ideas of life [15].

The spread of burnout is driven by global social, cultural and economic transformations. It is expected that this condition will become more widespread in developed industrial countries, due to the accelerated pace of life, the intensity of schedules and workloads, the need to compete with robots and computer algorithms. The transformation of the industrial society into a service economy significantly increases the psychological pressure on the individual. In Ukraine, the spread of burnout is affected by economic and political instability, the social vulnerability of workers, and environmental problems. The exact prevalence of burnout in Ukraine is unknown. According to a survey of the hh.ua recruitment portal, $64 \%$ of Ukrainians feel that they are experiencing emotional burnout syndrome [16]. It is to be considered that the methodology of this study was unscientific. Therefore the results obtained are more evidence of the concept than the prevalence of the real condition.

To date, there is a large number of academic publications, books, specialized journals, conferences covering this issue. A large amount of empirical data was gathered to actualize the necessity of revising the theoretical concept of burnout. In the 21st century, it is rather regarded as a blurring of a positive psychological state [4]. Scientists still lack a consistent understanding of burnout mechanisms. Understanding the problem depends significantly on the organizational context, social and national traditions (for example, in Sweden and the Netherlands, burnout is the official medical diagnosis), as well as on the purpose of the particular scientist. However, the accumulated knowledge is still unable to prevent the spread of burnout and its consequences among the working-age population. 
We assume that the apt definition of fatigue, "burnout", largely contributed to its popularization - it is implicitly understood in all languages, it is vivid, it does not trigger negative or alarming associations, and is even somewhat provocative. The metaphor of fire successfully represents the depletion of energy - a person once "burned", but the fire cannot burn brightly for a long time without constant and sufficient replenishment of resources. People eagerly acknowledge the symptoms of burnout, discuss them with interest, grateful to know they are not alone in their experiences. More and more high-profile celebrities publicly declare themselves "burned out", which on the one hand, promotes active public discussion of the issue, but unjustifiably simplifies this psychological symptom. There is a risk that phenomenon of burnout will be abused as an explanation of the excessively wide range of problem associated with fatigue, natural ageing, depression or a negative life situation. In this study, we attempted a psychological reconstruction of the concept of burnout in terms of its implicit understanding and differentiated diagnosis. Objectives of the study are to analyse the data obtained in direct interviews with clients of psychological counselling, as well as diagnostic evaluations of standardized questionnaires; to summarize empirical data on the prevalence of burnout among different categories of workers.

\section{MATERIALS AND METHODS}

A leading tool for comprehensive diagnosis of burnout syndrome all over the globe is the Maslach burnout inventory (MBI) questionnaire; its Russianlanguage version was adapted and standardized by N.E. Vodopyanova and A.S. Starchenko in 2003 [17]. The survey contains 22 statements regarding work- related experiences. Responses are rated on a 7-point Likert scale and range from "never" to "always". The results are calculated by evaluating three subscales: emotional exhaustion, depersonalization (cynicism) and professional achievement. Using a single questionnaire allows you to compare research data from different socio-cultural settings and professional settings. We conducted a statistical analysis of psychological diagnosis data obtained during 2015-2019 as part of empirical research on a variety of topics (postgraduate and master's theses that used the MBI questionnaire as a primary or auxiliary tool). It allowed to analyse the characteristics of burnout in professional groups, different in degree of personal responsibility and psycho-emotional involvement in work (Table 1):

- senior management and owners of large commercial enterprises;

leaders of the middle level of state institutions;

- small business owners and self-employed persons;

- ordinary employees of enterprises of various ownership;

- $\quad$ practical psychologists in the education system;

- $\quad$ social workers of public administration;

- $\quad$ university teachers:

- $\quad$ mobile network sellers;

- $\quad$ graduate students of the faculty of psychology.

The initial scale scores for the occupational burnout questionnaire were reviewed, the severity of burnout

Table 1: Characteristics of Professional Groups

\begin{tabular}{|c|c|c|c|c|}
\hline Professional group & Total number of persons & Number of women & Number of men & Age \\
\hline \hline $\begin{array}{c}\text { Executives and } \\
\text { business owners }\end{array}$ & 20 & 9 & 11 & $35-56$ \\
\hline Middle managers & 28 & 16 & 18 & $28-53$ \\
\hline Small entrepreneurs & 36 & 18 & 75 & $26-38$ \\
\hline Production workers & 160 & 18 & 0 & $24-45$ \\
\hline Practical psychologists & 18 & 35 & 0 & $33-55$ \\
\hline Social workers & 35 & 28 & 13 & $25-50$ \\
\hline University teachers & 41 & 8 & 32 & $20-32$ \\
\hline Sellers & 40 & 55 & 8 & $20-24$ \\
\hline Graduate students & 63 & 5 & \\
\hline
\end{tabular}


syndrome was determined for each respondent, and the frequency of prevalence of the issue in different socio-occupational groups was analysed. According to K. Maslach's burnout model, burnout, as a dynamic, evolving process of time, is characterized by an increase in the severity of individual manifestations. Each of the symptoms represents a separate stage in the development of this condition: first, there is emotional devastation to protect itself from the depletion of energy resources, and a person consciously or unknowingly tries to distance itself from the subjects of occupational activity, and alienation at work occurs. Furthermore, a negative attitude develops towards personal, professional achievements $[2,18]$.

Thus, we proceeded from the fact that the presence of chronic burnout is evidenced by the poor performance on all three subscales of the $\mathrm{MBI}$ methodology: high rates of emotional exhaustion and depersonalization, low scores on the scale of "professional efficiency" (reduction of personal achievements). We registered partial burnout with high ratings of symptoms of emotional exhaustion and depersonalization while retaining a sense of professional efficacy. Initial burnout is an emotional exhaustion that has not gone into a state of depersonalization and reduction of professional achievement. To interpret scale estimates, we relied on group norms obtained from large samples of socioeconomic professions [17]. We considered the results beyond the magnitude of $M \pm S D$ as meaningful results on a scale.

To clarify the symptoms of emotional burnout, we analysed the data of counselling conversations from our own psychological practice (20 people who volunteered for psychological help and complained about burnout as an element of difficult life situation: managers, entrepreneurs, politicians, journalists, medical professionals, etc.). The diagnostic materials and recordings made during the sessions were processed by the content analysis method: the content categories were separated, then the small units were grouped into more general classes, their prevalence was calculated (a percentage of the total number of observations). All participants were informed and consented to the use of their personal data in scientific publication; their anonymity is guaranteed.

\section{RESULTS}

Based on the primary diagnostic data, descriptive statistics were calculated in different samples (Table 2). The data show average trends and measures of distribution by individual burnout symptoms according to the activity type. This situation is most pronounced in the sample of social workers of public administration; the most favourable picture is in psychologists and sales associates. We also see that the severity of individual symptoms is professional in nature managers and business owners are characterized by depersonalization (negative, cynical attitude to the people they contact in their professional activities) with sufficient emotional involvement and recognition of personal achievements. Alumni students have a relatively less appreciation of personal, professional accomplishments, which is explained by a lack of professional experience.

We specified the dynamics of burnout development by dividing the respondents of each group according to the severity of the scores on three scales. The data in

Table 2: Primary Statistics for the Occupational Burnout Questionnaire in Different Samples (M \pm SD)

\begin{tabular}{|c|c|c|c|}
\hline \multirow{2}{*}{ Professional group } & \multicolumn{3}{|c|}{ Burnout symptoms } \\
\cline { 2 - 4 } & Emotional fatigue & $\begin{array}{c}\text { Depersonalization } \\
\text { (cynicism) }\end{array}$ & $\begin{array}{c}\text { Reduction of professional } \\
\text { achievements }\end{array}$ \\
\hline \hline Executives and business owners & $20.2 \pm 7.68$ & $12.5 \pm 4.06$ & $36.3 \pm 6.89$ \\
\hline Middle managers & $20.3 \pm 8.50$ & $10.4 \pm 4.35$ & $32.2 \pm 5.36$ \\
\hline Small entrepreneurs & $22.5 \pm 5.04$ & $9.1 \pm 4.37$ & $32.8 \pm 4.78$ \\
\hline Production workers & $21.6 \pm 7.34$ & $9.7 \pm 4.85$ & $33.2 \pm 9.09$ \\
\hline Practical psychologists & $20.1 \pm 5.12$ & $9.0 \pm 3.36$ & $34.5 \pm 6.60$ \\
\hline Social workers & $28.6 \pm 6.60$ & $13.4 \pm 3.89$ & $25.6 \pm 5.85$ \\
\hline University teachers & $22.5 \pm 8.81$ & $9.9 \pm 5.34$ & $32.5 \pm 6.83$ \\
\hline Sellers & $20.8 \pm 7.11$ & $9.2 \pm 5.68$ & $30.6 \pm 6.14$ \\
\hline Graduate students & $26.3 \pm 6.12$ & $10.5 \pm 4.09$ & $27.7 \pm 5.16$ \\
\hline
\end{tabular}


Table 3: Incidence of Burnout Symptoms in Different Samples, \%

\begin{tabular}{|c|c|c|c|c|c|}
\hline \multirow{2}{*}{ Professional group } & \multirow{2}{*}{$\begin{array}{l}\text { No signs of } \\
\text { burnout }\end{array}$} & \multicolumn{3}{|c|}{ Burnout degree } & \multirow{2}{*}{$\begin{array}{c}\text { Other } \\
\text { occupational/personal } \\
\text { deformities }\end{array}$} \\
\hline & & $\begin{array}{c}\text { Initial } \\
\text { phase } 1\end{array}$ & $\begin{array}{c}\text { Partial } \\
\text { phase 1, } 2\end{array}$ & $\begin{array}{c}\text { Chronic } \\
\text { phases } 1,2,3\end{array}$ & \\
\hline $\begin{array}{l}\text { Executives and business owners } \\
\qquad(\mathrm{N}=20)\end{array}$ & 30.0 & 10.0 & 5.0 & - & 55.0 \\
\hline Middle managers $(\mathrm{N}=28)$ & 53.6 & 14.2 & 10.7 & 3.6 & 17.9 \\
\hline $\begin{array}{l}\text { Small entrepreneurs } \\
\qquad(\mathrm{N}=36)\end{array}$ & 72.2 & 16.7 & - & - & 11.1 \\
\hline Production workers $(\mathrm{N}=160)$ & 70.6 & 5.6 & 6.9 & 3.8 & 13.1 \\
\hline Practical psychologists $(\mathrm{N}=18)$ & 55.5 & 22.2 & - & 5.6 & 16.7 \\
\hline Social workers $(\mathrm{N}=35)$ & 38.9 & 13.9 & 19.4 & 8.3 & 19.4 \\
\hline $\begin{array}{l}\text { University teachers } \\
\qquad(N=41)\end{array}$ & 78.0 & 7.4 & 2.4 & 2.4 & 9.8 \\
\hline $\begin{array}{l}\text { Sellers } \\
(N=40)\end{array}$ & 72.5 & 15.0 & 7.5 & - & 5.0 \\
\hline Graduate students $(\mathrm{N}=63)$ & 69.9 & 7.9 & 9.5 & 6.3 & 6.3 \\
\hline
\end{tabular}

Table 3 represent burnout as a dynamic process that unfolds over time and has certain phases. But not all individual cases fit into this theoretical model. Most of the respondents had an increased rate of depersonalization in the absence of complaints of emotional exhaustion. This may be related to other professional identity disorders or personal disorders unrelated to burnout syndrome.

As can be seen from the distribution of data, the presence of symptoms in different groups is clearly different: the signs of burnout are entirely absent in over $70 \%$ of production workers, salespeople and teachers. Obviously, these areas do not imply high levels and chronic duration of occupational stress. For private entrepreneurs, burnout is absent or observed only in its initial phase, indicating a balance of energy costs and resources (this activity can be stressful, but provides sufficient rewards for the effort spent). Practical psychologists show some emotional and motivational exhaustion (22.2\%), but their professional skills imply the ability to recognize and regulate this condition.

With that, a considerably large proportion of observations does not fit into the procedural and dynamic model. Over half (55\%) of large business executives and $17.9 \%$ of government executives display express cynicism and depersonalization without any other signs of burnout. Among the psychologists of the education system, the opposite pattern is often found - emotional and motivational fatigue and reduction of professional achievements in the absence of cynicism. Depreciation of personal, professional achievements is a common symptom among social workers $(19.4 \%)$. This requires clarification of the phenomenological signs of emotional burnout. Proceeding from personal counselling practice, interviews with people experiencing and describing this condition, we have compiled a list of specific experiences and behaviours:

Emotional sphere (100\% of respondents):

- Loss of vital energy and inability to restore it in the usual way: "I just laid on the couch for a month", "I have neither the strength nor the desire", "lazy to do anything", "I can only dream of rest".

- Inability to enjoy the professional activity and other activity that was previously perceived positively and even resourcefully.

- $\quad$ Feeling uneasy, worrying thoughts, anxious tension.

Motivational and conceptual sphere $(90 \%$ of respondents):

Loss of motivation, lack of initiative. Abandoning goals that previously seemed necessary.

- Reappraisal of values both in the professional sphere and in normal life increased.

Feeling of meaningless existence, loss of interests not only to work but also to leisure, relationships, etc.: "lost life", hopelessness. 
Indifference to self, to personal well-being, which grows into apathy to others; gradually, more and more significant persons are included in this circle.

- Loss of interest in hobbies, creativity, social activity.

Life philosophy and lifestyle ( $85 \%$ of respondents):

- $\quad$ Changing attitude: the word "disappointment" is most often used in self-reports. This applies to self, other people and the world at large.

Reduced self-esteem, self-loathing, self-doubt.

Painful guilt, self-blame.

Dissatisfaction with personal lifestyle while unwilling to change something.

Loss of positive life prospects, expectation of trouble, negative re-evaluation of personal past.

- Loss of sense of personality, control of life. "Helplessness". The person feels they need help, wants support from loved ones or professional help but does not know what to do.

- Distrust of people and the world at large, negative expectations.

Self-justification, indulgence of weaknesses: alcohol and other stimulants, shopogolism, overeating, gambling, etc. Failure to control personal weaknesses leads to frequent selfjustification, work of defence mechanisms (rationalization).

Behavioural manifestations ( $70 \%$ of respondents):

Inactivity in situations that require activity.

Ignoring existing problems, distancing or transferring responsibility to others, postponing decisions, "self-sabotage".

Avoiding cognitive and physical effort.

Avoiding interpersonal contacts, feelings of loneliness, self-isolation, complaints of misunderstanding on the part of loved ones.

Procrastination in performing work or life tasks.

Reduced performance: what used to be easy, takes a lot of time and effort, "work becomes more difficult", the difficulty of generating creative ideas.

Psychophysiological manifestations $(100 \%$ of respondents):

Feeling of constant fatigue (mental fatigue precedes physical fatigue).

Physical discomfort, impaired functioning of various organs and systems: difficulty falling asleep, skin problems, pain in muscles and joints, weight loss or gain, hair loss, nausea, dizziness, feeling of heaviness, fluctuations in blood pressure and palpitations (very individually, indicating psychosomatic origin).

\section{DISCUSSION}

Comparison of the burnout statistics in individual occupational groups with data from similar previous studies was challenging, as many domestic scientists prefer the V.V. Boyko questionnaire, which analyses this syndrome using 12 scales combined into three factors corresponding to the stages of stress, resistance, and fatigue [18]. Due to the inconsistency of the theoretical models underlying the diagnostic tools, direct matching is impossible. When looking at the data from the $\mathrm{MBI}$ questionnaire, we noticed a sharp discrepancy between the results in percentage terms (the average statistics, however, generally match). It was discovered that often people with burnout symptoms include subjects who have an average level of symptoms according to statistical norms (i.e., fall in the $M \pm S D$ interval). This leads to an unnecessary overestimation of statistics - up to $70 \%$ of "burned out" people.

Such a situation requires clarification of the methodological aspects of diagnostics - the definition of clear socio-psychological standards that reliably diagnose the symptoms of burnout. We shall remind that when operating the term "expressed burnout", one should rely on empirical results that go beyond the statistical norm. Thus, the symptoms of burnout are evidenced by the indicators on the scales "Emotional exhaustion" and "Depersonalization", which are in the range from $M+S D$ to $M+2 S D$ (overestimated in accordance with the norm) or from $M+2 S D$ to $M+3 S D$ (significant excess of regulatory values). The "Professional achievement reduction" scale is interpreted in the reverse order - indicators ranging from $M-S D$ to $M-2 S D$ (reduced according to the norm) 
and from M-2SD to M-3SD (distinctly low) are unfavourable. With that, it is important to bear in mind the relativity of statistical norms and the necessity of their constant updating. The sampling standardization is of key importance - the results we obtained demonstrate the extent to which the prevalence of basic burnout patterns differs across different age and occupational groups.

Such an approach facilitates a more realistic picture of the prevalence. Thus, according to the analytical report of T.V. Brizhovaty et al., among humanitarian workers operating in the field of military conflict management in the east of Ukraine, $42 \%$ have a high level of professional burnout, another $36 \%$ display an average $\mathrm{MBI}$ indicator, and $22 \%$ - a low one [19]. This corresponds to the statistics of our study and indicates the reliability of the results obtained. The findings also confirm our observation that significant manifestations of occupational burnout are most commonly seen in the form of depersonalization and cynicism. L.L. LototskaHolub study reveals the prevalence of depersonalization and the relative rarity of admitting personal, professional inefficacy among physicians (the same pattern was described in the sample of managers) [20]. Such manifestations can arise as mechanisms of psychological protection in the professionalization process.

Concerning the refinement of the phenomenological features of emotional burnout according to the counselling practice, it is evident that the majority of the descriptions fit into the classic picture described by $\mathrm{K}$. Maslach [2]. With that, people point little to the third component, which is associated with increased work errors and loss of professional efficacy. This does not mean that these manifestations are objectively absent; most likely, due to positive self-esteem protection mechanisms, they are noticed and admitted the last. The results of diagnostics confirm this assumption - by the third $\mathrm{MBI}$ scale, almost no severe cases were detected. Instead, clients of psychological counselling point to the "severity", "soreness" of professional efforts, self-pressure, unwillingness to engage in previously favourite activities.

Many of the characteristic signs of burnout are similar to the symptoms of clinical depression: in both states, a person is tired, passive, indifferent, deprived of energy, pessimistic, dissatisfied with themselves and the environment, irritable, indecisive, avoids social bonds and loses the capacity to work. Emotional burnout and depression are often considered as related problems in the literature, but there is a clear difference between them, which is defined by cortisol levels. Upon burnout, the lack of this hormone is noted, as a consequence - a decrease in strength and a reduced reaction to stress; and in depression, cortisol is in excess [10].

Burnout touches on the highest personal dispositions - meanings, values, life goals, wherein lies its significant difference from mere fatigue. Partially described experiences intersect with the symptoms of existential crises: the reassessment of values and life prospects is inherent in the "midlife crisis". Emotional hyper-reactivity or emotional indifference reflects the degree of burnout - in the latter case, much more effort and recovery time are required. Most people in the early stages can restore self-regulation themselves. The crucial thing is to ensure rest and the opportunity to switch from activities that led to disappointment and fatigue.

\section{CONCLUSIONS}

The prevalence of burnout in some groups is large enough to lead to significant social consequences apathy and impaired professional performance. Its symptomatology differs quantitatively and qualitatively in various professional environments, depending on the age, nature of activity and frequency of professional stress, degree of personal responsibility, emotional involvement in the work. The obtained data significantly broaden the understanding of the manifestations of emotional burnout syndrome, allowing to review and update the knowledge of this phenomenon.

Awareness, prevention and early psychological support are essential to overcome burnout as a social phenomenon. Unfortunately, self-diagnosis and seeking medical advice usually occur when the pattern of the disorder is instead express and straightforward. Therefore, the primary perspective we consider is selfhelp - the improvement of self-regulation skills based on the enhancement of psychological culture, awareness of the stages and consequences of burnout. It is essential to prioritize, exercise self-care for personal psychological wellness and physical health. Besides, large-scale institutional efforts are required, along with national and international programs aimed at combating burnout.

The main focus of burnout prevention is the balance of effort and resources. On the one hand, these are professional (life) requirements that involve physical 
and mental costs, on the other hand, the physical and social aspects of the work (living) environment, including personal psychological resources that assist in the accomplishment of set tasks. Achieving this balance is a matter of both an organization interested in its prosperity through the efficient use of human resources and a specific individual who knows their own needs, goals, opportunities and limitations.

We would like to draw attention to the necessity of clarification of social-psychological norms and clinical signs, which reliably and differentially diagnose the symptoms of emotional burnout (in contrast to fatigue, depression or normative age crises).

\section{ACKNOWLEDGEMENT}

The authors appreciate the referees' valuable and profound comments that helped to improve the submitted manuscript significantly.

\section{REFERENCES}

[1] Hillert A, Marwitz M. Die burnout-epidemie: oder brennt die leistungsgesellschaft aus? Munchen: Verlag C.H. Beck 2006.

[2] Maslach C, Leiter MP. The truth about burnout: how organizations cause personal stress and what to do about it. San Francisco: Jossey-Bass 1997.

[3] Leon MJ, Halbesleben S, Paustian-Underdahl. A dialectical perspective on burnout and engagement. Burnout Research 2015; 2(2-3): 87-96.

[4] Schaufeli WB, Leiter MP, Maslach C. Burnout: 35 years of research and practice. Career Development International 2009; 14: 204-220. https://doi.org/10.1108/13620430910966406

[5] Leka S, Jain A. World Health Organization. Health impact of psychosocial hazards at work: an overview. Geneva: WHO Press, 2010.

[6] Golkar A. The influence of work-related chronic stress on the regulation of emotion and on functional connectivity in the brain. PLoS One 2014; 9(9): 45-49.

https://doi.org/10.1371/journal.pone.0104550
[7] Savic I. Structural changes of the brain in relation to occupational stress. Cerebral Cortex 2015; 25: 1554-1564. https://doi.org/10.1093/cercor/bht348

[8] Michel A. Burnout and the brain. Observer 2016; 29(2). https://www.psychologicalscience.org/observer/burnout-andthe-brain.

[9] Oosterholt BG, Maes JH, Van der Linden D, Verbraak MJ, Kompier MA. Burnout and cortisol: evidence for a lower cortisol awakening response in both clinical and nonclinical burnout. Journal of Psychosomatic Research 2015; 78: 445451.

https://doi.org/10.1016/j.jpsychores.2014.11.003

[10] Pruessner JC, Hellhammer DH, Kirschbaum C. Burnout perceived stress, and cortisol responses to awakening Psychosomatic Medicine 1999; 61(2): 197-204. https://doi.org/10.1097/00006842-199903000-00012

[11] Bohomolets O. Emotional burnout can become a new "epidemic" of humanity. Ukrainska Pravda. 2019. Available at: https://blogs.pravda.com.ua/authors/bogomolec/ $5 \mathrm{cf0dd} 9 \mathrm{a} 87 \mathrm{~b} 5 \mathrm{e} /$.

[12] Occupational burnout is a phenomenon, not a disease: What was actually confirmed in ICD-11. 2019. Available at: https://moz.gov.ua/.

[13] International classification of diseases: "occupational syndrome" of emotional burnout. World Health Organization. 2019; Available at: https://www.who.int/.

[14] Izyumskaya A. Mom's tapped out. Guide to the parental burnout. Moscow: Samokat, 2018.

[15] Vagin YuR. Non-Occupational Burnout Syndrome. Formula Krasoti 2015; 1(70): 44-45.

[16] Emotional burnout: which professions are in crosshairs. 2017. Available at: https://kiev.hh.ua/article/20456.

[17] Vodopyanova NE. Standardized questionnaire "Occupationa burnout" for specialists in socioeconomic professions. Vestnik of Saint Petersburg University 2013; 4: 17-27.

[18] Vodopyanova NE. Burnout Syndrome. Diagnostics and Prevention. Moscow: Urait, 2017.

[19] Bryzhovatyi TV, Volhina OM, Halai AO, Dmytriiev DO Analytical report on the results of the study "Evaluation of the level of professional burnout of humanitarian workers". Kyiv: Ukraine NGO Forum 2013.

[20] Lototska-Holub LL. Features of influence of communicative skills on manifestations of emotional burnout of doctors. Naukovyi Chasopys of M.P. Drahomanov National Pedagogical University. Series 12: Psychological Sciences 2014; 44: 232-239.

\section{DOI: https://doi.org/10.6000/2292-2598.2020.08.01.5}

(C) 2020 Bocheliuk et al.; Licensee Lifescience Global.

This is an open access article licensed under the terms of the Creative Commons Attribution Non-Commercial License (http://creativecommons.org/licenses/by-nc/3.0/) which permits unrestricted, non-commercial use, distribution and reproduction in any medium, provided the work is properly cited. 